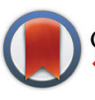

CrossMark \& click for updates

Cite this: Food Funct., 2016, 7, 1176

\title{
Formation of malondialdehyde (MDA), 4-hydroxy- 2-hexenal (HHE) and 4-hydroxy-2-nonenal (HNE) in fish and fish oil during dynamic gastrointestinal in vitro digestion $\uparrow$
}

\author{
Karin Larsson, ${ }^{\text {a }}$ Hanna Harrysson, ${ }^{a}$ Robert Havenaar, ${ }^{\text {b }}$ Marie Alminger ${ }^{\mathrm{a}}$ and \\ Ingrid Undeland ${ }^{a}$
}

\begin{abstract}
Marine lipids contain a high proportion of polyunsaturated fatty acids (PUFA), including the characteristic long chain (LC) n-3 PUFA. Upon peroxidation these lipids generate reactive products, such as malondialdehyde (MDA), 4-hydroxy-2-hexenal (HHE) and 4-hydroxy-2-nonenal (HNE), which can form covalent adducts with biomolecules and thus are regarded as genotoxic and cytotoxic. PUFA peroxidation can occur both before and after ingestion. The aim of this study was to determine what levels of MDA, HHE and HNE can evolve in the gastric and intestinal lumen after ingesting meals containing fish or fish oil using a dynamic gastrointestinal (GI) model (TIM). The impact of the fish muscle matrix, lipid content, fish species, and oven baking on Gl oxidation was evaluated. MDA and HHE concentrations in gastric lumen increased for all meals during digestion, with the highest level found with herring mince; 25 $\mu \mathrm{M}$ MDA and $~ 850 \mathrm{nM} \mathrm{HHE}$. Aldehyde concentrations reached in intestinal lumen during digestion of fish containing meals were generally lower than in gastric lumen, while isolated herring oils (bulk and emulsified) generated higher MDA and HHE values in intestinal lumen compared to gastric lumen. Based on aldehyde levels in gastric lumen, meals containing herring lipids were ranked: raw herring $(17 \%$ lipid $)=$ baked herring ( $4 \%$ lipid) $>$ raw herring ( $4 \%$ lipid) $\gg$ herring oil emulsion $>$ herring oil. Herring developed higher concentrations of MDA and HHE during gastric digestion compared to salmon, which initially contained lower levels of oxidation products. Cooked salmon generated higher MDA concentrations during digestion than raw salmon. Low levels of HNE were observed during digestion of all test meals, in accordance with the low content of $n-6$ PUFA in fish lipids.
\end{abstract}

Received 18th November 2015, Accepted 21st January 2016

DOI: $10.1039 / \mathrm{c} 5$ fo01401h

www.rsc.org/foodfunction

\section{Introduction}

Lipid oxidation is a problem during storage and processing of lipid containing food, especially foods of marine origin rich in polyunsaturated fatty acids (PUFA). Not only does lipid oxidation negatively affect the sensory properties of the marine food item, but it may also hamper the documented abilities of the long chain (LC) n-3 PUFA, such as eicosapentaenoic acid (EPA) and docosahexaenoic acid (DHA), to protect against e.g. cardiovascular disease ${ }^{1}$ and inflammation. ${ }^{2}$ This is since LC n-3 PUFA oxidation can give rise to several toxic degradation

\footnotetext{
${ }^{a}$ Department of Biology and Biological Engineering-Food and Nutrition Science, Chalmers University of Technology, Gothenburg, Sweden.

E-mail: karin.larsson@chalmers.se; Fax: +46(0)31-772 38 30;

Tel: $+46(0) 31-7723811$

${ }^{b}$ TNO Triskelion, Utrechtseweg 48, 3704 HE Zeist, The Netherlands

$\dagger$ Electronic supplementary information (ESI) available. See DOI: 10.1039/ c5fo01401h
}

products. Many studies have shown that lipid oxidation also can occur during gastric and gastrointestinal (GI) digestion of lipid containing foods and supplements. ${ }^{3-7}$ As summarized by Halliwell et al., ${ }^{3}$ reasons contributing to this can be the presence of dietary pro-oxidants, e.g. iron ions, copper ions, lipid/ hydrogen peroxides and heme-proteins, in combination with the low $\mathrm{pH}$ in the gastric phase and the action of digestive compounds. Most previous studies on this topic have however been made on meat ${ }^{4-8}$ or vegetable oils. ${ }^{9-12}$ There are few studies that have addressed GI oxidation of the typical marine fatty acids ${ }^{13-15}$ despite their susceptibility towards oxidation, and only one of these studies dealt with fish. ${ }^{16}$ Certain fish species, like the small pelagic ones (e.g. herring, sardines), contain high levels of hemoglobin and myoglobin, compounds, which can be further activated as pro-oxidants under gastric conditions. ${ }^{17}$ Other species, such as salmon and rainbow trout carry high levels of antioxidative pigments in the form of astaxanthin. It is not known how GI oxidation of fish lipids is affected by the presence or absence of the fish muscle 
matrix, i.e. when the lipids are isolated as oil versus when they are present in the intact fish muscle.

Over the years there has been an increasing focus on electrophilic reactive aldehydes, which can be formed as secondary oxidation products during the decomposition of polyunsaturated lipid hydroperoxides. Examples of such aldehydes are $\alpha$-, $\beta$-unsaturated aldehydes, e.g. 4-hydroxy-2-nonenal (HNE), 4-hydroxy-2-hexenal (HHE), and malondialdehyde (MDA). These aldehydes have been described as potentially cytotoxic and mutagenic and they are all oxidation products originating from PUFA; HHE is formed from n-3 PUFA, HNE is formed from n-6 PUFA, while MDA is formed from both series. ${ }^{18}$ The level of $\alpha$-, $\beta$-unsaturated aldehydes that potentially could be formed in the GI tract after intake of a fish meal has so far not been reported. Such information would be highly relevant in order to allow extrapolation of results from toxicological studies of pure $\alpha$-, $\beta$-unsaturated aldehydes to an expected postprandial situation. This enables the estimation of potential negative health effects from GI aldehyde generation. Literature reports e.g. a link between HNE and MDA on inflammatory bowel diseases, such as Crohn's disease. ${ }^{19}$

Except one, ${ }^{16}$ all the mentioned in vitro digestion studies focusing on lipid oxidation have been carried out in a static manner. The advantages of a dynamic model such as the TNO gastrointestinal model (TIM) is that it enables continuous secretion of physiological solutions, and mimics the gradual change in $\mathrm{pH}$ of the stomach and the small intestine after intake of a meal, as well as simultaneous gastric emptying and intestinal removal of water- and lipid-soluble compounds from the digesta. To obtain a more realistic picture over the levels of lipid oxidation products the GI mucosa are subjected to during digestion, dynamic methods are to prefer over static ones.

The aim of the present study was to analyze the MDA, HHE and HNE levels formed during digestion of fish and fish oil in the TIM system. Two common food fish species rich in LC n-3 PUFA were investigated; baltic herring with high levels of heme-proteins and farmed salmon with high levels of astaxanthin. Due to the large seasonal variation in lipid content of herring, two different batches were compared from a GI oxidation perspective. To study the effect of the fish muscle matrix per se, the GI oxidation of fish mince was compared with its corresponding fractionated oil alone. Further, the effect of oven baking of the fish on GI oxidation was investigated. The formed oxidation products were evaluated in relation to potential health risks.

\section{Materials and methods}

\subsection{Chemicals}

Pepsin (2188 $\mathrm{U} \mathrm{mg}^{-1}$ ) from porcine gastric mucosa, $\alpha$-amylase (1333 $\mathrm{U} \mathrm{mg}^{-1}$ ) from Bacillus sp., trypsin from bovine pancreas, 1,1,3,3-tetraethoxypropane, 2,4-dinitrophenylhydrazine (DNPH) and ascorbic acid were purchased from Sigma-Aldrich (Stockholm, Sweden). Lipase F-AP 15 (150 U mg $\left.\mathrm{mg}^{-1}\right)$ from
Rhizopus oryzae was obtained from Amano Enzyme Inc. (Nagoya, Japan). Fresh porcine bile was obtained from TNO (Zeist, The Netherlands). Pancreatin (Pancrex-Vet, Pfizer, Karlsruhe, Germany) was purified by centrifugation $(9000 \mathrm{~g}, 20 \mathrm{~min}$, $4{ }^{\circ} \mathrm{C}$ ) before use. Wheat flour bread containing $1 \%$ vegetable oil $(0.4 \%$ saturated) was purchased in a local supermarket. C17:0 and the fatty acid methyl ester (FAME) standard mixture GLC364 were from Nu-Check Prep (Elysian, MN, USA) and 4-hydroxy-2-hexenal (HHE) and 4-hydroxy-2-hexenal (HNE) were purchased from Cayman Chemicals (Ann Arbor, MI, USA). All other chemicals used were of analytical grade.

\subsection{Fish and fish oil}

High fat herring (Clupea harengus) was caught in the Baltic Sea in June 2011 and obtained from Leröy Allt i Fisk (Göteborg, Sweden), while low fat herring was caught in Skagerrak in February 2012 and supplied by Paul Mattson AB (Ellös, Sweden). Farmed Atlantic salmon (Salmo salar), 5-6 kg, was harvested by SalMar ASA (Kverva, Norway) in February 2012 and purchased from Landala Fisk (Göteborg, Sweden). Butterfly fillets $\left(\begin{array}{ll}\sim 100 & \mathrm{~g}\end{array}\right)$ from both lots of herring were received in the laboratory two days post mortem, while the whole gutted fresh salmon was filleted and received in the laboratory three days after harvest. After de-skinning, fillets were ground in a kitchen grinder (Ultra Power Model KSM90, Kitchen Aid, St Joseph, MI, USA), equipped with a hole plate with holes of $5 \mathrm{~mm} \varnothing$ to obtain "raw mince". Cooking of low fat herring and salmon was prepared by oven baking $\left(125^{\circ} \mathrm{C}\right)$ of whole herring fillets and pieces $(\sim 200 \mathrm{~g} \times 3)$ representing the whole fillet of one salmon fillet to an inner temperature of $55{ }^{\circ} \mathrm{C}$ with subsequent grinding. Herring oil was prepared from the high fat herring by centrifugation of the minced herring fillets at $18400 \mathrm{~g}$ for $30 \mathrm{~min}$ at $20{ }^{\circ} \mathrm{C}$. The floating herring oil was collected and split into aliquots. Raw and oven baked fish minces and fish oils were kept frozen at $-80{ }^{\circ} \mathrm{C}$ until use.

\subsection{Preparation of test meals}

Test meals, including simulated saliva (see below), were freshly prepared prior to feeding into the dynamic GI model. Frozen fish mince and herring oils were thawed in ice-water. Oil-inwater emulsion $(20 \% \mathrm{w} / \mathrm{w})$ was prepared on the day of use by homogenizing herring oil with an emulsifier solution $(17 \mathrm{mM}$ Brij 35 in $10 \mathrm{mM}$ phosphate buffer, $\mathrm{pH}$ 7.0) for $2 \mathrm{~min}$ at 24000 rpm while kept on ice (CAT X620, M. Zipperer $\mathrm{GmbH}$, Germany). Simulated saliva ( $\mathrm{NaCl} 6.2 \mathrm{~g} \mathrm{~L}^{-1}, \mathrm{KCl} 2.2 \mathrm{~g} \mathrm{~L}^{-1}$, $\mathrm{CaCl}_{2} \cdot 2 \mathrm{H}_{2} \mathrm{O} 0.3 \mathrm{~g} \mathrm{~L} \mathrm{~L}^{-1}$, amylase $0.007 \mathrm{~g}$ per meal), deionized water, and either fish mince (oven baked or raw), oil or emulsion were mixed according to the weights presented in Table 1. Wheat flour bread was included as a bulk to ensure proper gastric emptying when using crude herring oil, but was in selected cases also added to other test meals to avoid background differences (Table 2). The $\mathrm{pH}$ of the meal was adjusted to 6.5 with $1 \mathrm{M} \mathrm{NaHCO}_{3}$ and, for convenience, $5 \mathrm{~g}$ of gastric residue $\left(\mathrm{NaCl} 6.2 \mathrm{~g} \mathrm{~L}^{-1}, \mathrm{KCl} 2.2 \mathrm{~g} \mathrm{~L}^{-1}, \mathrm{CaCl}_{2} \cdot 2 \mathrm{H}_{2} \mathrm{O} 0.3 \mathrm{~g} \mathrm{~L}^{-1}\right.$, pepsin $264 \mathrm{mg} \mathrm{L}^{-1}$ and lipase $248 \mathrm{mg} \mathrm{L}^{-1}$ ) was added to the 
Table 1 Composition of a $150 \mathrm{~g}$ portion (intake) of each test meal digested in the dynamic $\mathrm{Gl}$ model

\begin{tabular}{lllll}
\hline & $\begin{array}{l}\text { Saliva } \\
(\mathrm{g})\end{array}$ & $\begin{array}{l}\text { Bread } \\
(\mathrm{g})\end{array}$ & $\begin{array}{l}\text { Water } \\
(\mathrm{g})\end{array}$ & $\begin{array}{l}\text { Fish mince/ } \\
\text { oil/emulsion } \\
(\mathrm{g})\end{array}$ \\
\hline $\begin{array}{l}\text { Herring/salmon mince } \\
\text { (bread/no bread) }\end{array}$ & 20 & $20 / 0$ & $60 / 80$ & 50 \\
$\begin{array}{l}\text { Herring oil } \\
\begin{array}{l}\text { Herring oil emulsion } \\
\text { Blank (bread/no bread) }\end{array}\end{array}$ & 20 & 20 & 101.25 & 8.75 \\
& 20 & 0 & 86 & 44 \\
& & $20 / 0$ & $110 / 130$ & 0
\end{tabular}

Table 2 Number of digestion experiments in the dynamic Gl model of each test meal with specification of number of replicates with and without the addition of a wheat flour bread used as bulk

\begin{tabular}{llll}
\hline Test meal & $\begin{array}{l}\text { Digestion } \\
\text { exp. }\end{array}$ & $\begin{array}{l}\text { With } \\
\text { bread }\end{array}$ & $\begin{array}{l}\text { Without } \\
\text { bread }\end{array}$ \\
\hline Blank & 3 & 2 & 1 \\
Herring oil & 1 & 1 & \\
Herring oil emulsion & 2 & 2 & 2 \\
Herring (17\%) raw & 4 & 2 & \\
Herring (4\%) raw & 2 & 2 & 2 \\
Herring (4\%) baked & 4 & 1 & \\
Herring (4\%) baked + asc & 1 & 2 & \\
Salmon raw & 2 & 2 & \\
Salmon baked & 2 &
\end{tabular}

asc $=$ ascorbic acid $\left(85 \mu \mathrm{M}\right.$ in gastric secretions, $\left.1 \mathrm{~mL} \mathrm{~min}^{-1}\right)$.

test meal prior to feeding. Blank digestions (with or without bread) were included to determine the background level of oxidation products in the model, which in the results have been subtracted from the test meals. In order to determine the intrinsic "dilution" of the intake meal at each sampling point during the digestion, which occurred due to the continuous secretion and absorption, as well as the samplings, two "dilution blanks" were run. The dilution blank consisted of a blue coloring agent dissolved in electrolyte solution (Patent Blue V sodium salt, Sigma-Aldrich, Stockholm, Sweden), and the change in concentration was followed by absorbance readings at $638 \mathrm{~nm}$ throughout the simulated digestion.

\subsection{Gastrointestinal model, tiny-TIM}

The dynamic computer-controlled TIM-1 system (TNO gastrointestinal model, Zeist, Netherlands) simulating four successive compartments (stomach, duodenum, jejunum and ileum) has been described in detail by Minekus et al. ${ }^{20}$ In this study an adapted model of TIM- 1 called tiny-TIM has been used. ${ }^{21}$ Tiny-TIM is a two compartments model where the three small intestinal sections have been combined to one, which simulates the average actions of the duodenum and jejunum. The stomach and small intestine are comprised by flexible silicon walls, which are surrounded by outer glass jackets. The compartments are temperature regulated at $37{ }^{\circ} \mathrm{C}$ by circulating water between the silicon walls and the glass jackets. The peristalsis of the stomach and small intestine for the mixing of the chyme is mimicked by changing the water pressure in the different parts of the system in a controlled way. Computercontrolled pumps regulates the secretions of hydrochloric acid ( $0.5 \mathrm{M}$ or milli-Q water) and simulated gastric juice $(\mathrm{NaCl} 3.1$ $\mathrm{g} \mathrm{L}^{-1}, \mathrm{KCl} 1.1 \mathrm{~g} \mathrm{~L}^{-1}, \mathrm{CaCl}_{2} \cdot 2 \mathrm{H}_{2} \mathrm{O} 0.15 \mathrm{~g} \mathrm{~L}^{-1}$, pepsin $132 \mathrm{mg} \mathrm{L}^{-1}$ and lipase $\left.124 \mathrm{mg} \mathrm{L}^{-1}\right)$ to the stomach $\left(1 \mathrm{~mL} \mathrm{~min}^{-1}\right)$, and sodium bicarbonate $(1 \mathrm{M})$, pancreatic juice (pancreatin 17.5 $\mathrm{g} \mathrm{L} \mathrm{L}^{-1}$, NaCl $1.25 \mathrm{~g} \mathrm{~L}^{-1}$, KCl $0.15 \mathrm{~g} \mathrm{~L}^{-1}$ and $\mathrm{CaCl}_{2} \cdot 2 \mathrm{H}_{2} \mathrm{O}$ $\left.0.075 \mathrm{~g} \mathrm{~L}^{-1}\right)$ and bile to the small intestine $\left(1 \mathrm{~mL} \mathrm{~min}^{-1}\right)$. Two $\mathrm{pH}$ electrodes are connected to the system to adjust the $\mathrm{pH}$ of the gastric and the small intestinal lumen according to programmed $\mathrm{pH}$ profiles. The composition and amount of secretion solutions, as well as the $\mathrm{pH}$ profiles, are set to simulate the physiological conditions after the intake of a meal. Gastric emptying is regulated by valve pumps, opening or closing the valves between the gastric and the small intestinal compartments to simulate the pyloric sphincter. In this study, the model was programmed to simulate adult human digestion of a semi-solid food. The half-time of gastric emptying was $70 \mathrm{~min}$. Connected to the small intestinal compartment was a hollow fiber module (MiniKros® Plus M80S-300-01P, Spectrum Laboratories, Inc. Rancho Dominguez, CA, USA) consisting of a semipermeable membrane with a pore size of $50 \mathrm{~nm}$. This enables a simulated absorption of water- and lipid-soluble compounds $\left(\sim 2 \mathrm{~mL} \mathrm{~min}^{-1}\right)$ from the small intestine. Prior to feeding, an intestinal residue consisting of $35 \mathrm{~mL}$ bile, $35 \mathrm{~mL}$ pancreatin $\left(35 \mathrm{~g} \mathrm{~L}^{-1}\right)$ and $70 \mathrm{mg}$ trypsin was added to the intestinal compartment of the model. The gastric residue was added directly to the test meal just before feeding as described above. Each digestion experiment lasted for at least $180 \mathrm{~min}$. To follow the change in concentration of lipid oxidation products during a longer time scale, some digestions were run for $300 \mathrm{~min}$. Samples from the gastric and intestinal lumen were withdrawn at 30,60,90,120,150, and $180 \mathrm{~min}$ of digestion. The intestinal absorption samples were collected in $30 \mathrm{~min}$ aliquots (0-30 $\mathrm{min}, 30-60 \mathrm{~min}$ etc.) for $180 \mathrm{~min}$, which means that each sampling point (e.g. $60 \mathrm{~min})$ represents the total absorption volume collected between two luminal sampling points (in this case: $30-60 \mathrm{~min}$ ). For the experiments with a prolonged digestion time (300 min instead of $180 \mathrm{~min}$ ), intestinal lumen were also withdrawn at 240 and $300 \mathrm{~min}$ and intestinal absorption samples in 180-240 min and 240-300 min aliquots. Sample aliquots were stored at $-80{ }^{\circ} \mathrm{C}$ until analysis.

\subsection{Analysis of lipid content and fatty acid pattern}

The total lipid content of fish minces and bile was determined gravimetrically after extraction with chloroform and methanol according to Lee et al., ${ }^{22}$ using $2 \mathrm{~g}$ of fish mince or bile. The evaporated lipid extract was dissolved in toluene for subsequent methylation and fatty acid analysis. Crude oils were diluted directly in toluene. Fatty acid composition was determined after conversion of the fatty acids to methyl esters according to the method of Lepage and Roy. ${ }^{23}$ Briefly, $1 \mathrm{ml}$ of diluted lipid extract was mixed with an internal standard (C17:0), followed by the addition of $2 \mathrm{~mL}$ toluene and $2 \mathrm{~mL}$ 
acetyl chloride dissolved in methanol (10\% v/v). Samples were incubated overnight at room temperature and thereafter $1 \mathrm{~mL}$ deionized water (Millipore) was added. FAME were extracted once with $2 \mathrm{~mL}$ petroleum ether and were, after evaporation under a stream of $\mathrm{N}_{2}$ gas, dissolved in $500 \mu \mathrm{L}$ isooctane. The FAME were separated by gas chromatography (7890A; Agilent Technologies $)$ on a DB-WAX column $(30 \mathrm{~m} \times 0.25 \mathrm{~mm} \times$ $0.25 \mu \mathrm{m}, \mathrm{J} \& \mathrm{~W}$ Scientific, CA, USA) and quantified with a 5975C inert XL EI/CI MSD with triple-axis detector (Agilent Technologies) after electron ionization. The methylated fatty acid mixture GLC 364 (Nu-Check Prep, Elysian, MN, USA) was used for identification of the different peaks. Lipids were extracted and analyzed in triplicates.

\subsection{Analysis of MDA, HHE, and HNE}

The amount of MDA, HHE and HNE were determined by LC/APCI-MS in gastric and intestinal lumen samples as well as in intestinal absorption samples after derivatization with DNPH. The method is described by Tullberg et al. ${ }^{24}$ Briefly, $500 \mu \mathrm{L}$ sample (digesta or intake sample) was mixed with $20 \mu \mathrm{L}$ BHT $\left(1 \mathrm{mg}_{\mu} \mathrm{L}^{-1}\right), 40 \mu \mathrm{L} \operatorname{EDTA}(0.02 \mathrm{M})$ and $500 \mu \mathrm{L} 0.25$ $\mathrm{M} \mathrm{HCl}$, vortexed and incubated for $5 \mathrm{~min}$. Precipitated proteins were separated by centrifugation $\left(16000 \mathrm{~g}\right.$ for $2 \mathrm{~min}$ at $\left.20^{\circ} \mathrm{C}\right)$. Derivatization of aldehydes was performed by mixing $400 \mu \mathrm{L}$ supernatant with $25 \mu \mathrm{L} \mathrm{DNPH}\left(2 \mathrm{mg} \mathrm{mL}^{-1}\right.$ in $\left.\mathrm{MeOH}\right)$ and incubated for $1 \mathrm{~h}$ at room temperature. Derivatives were extracted twice with $500 \mu \mathrm{L}$ dichloromethane $(16000 \mathrm{~g}$ for $2 \mathrm{~min}$ at $20{ }^{\circ} \mathrm{C}$ ) and pooled extracts were evaporated under a stream of $\mathrm{N}_{2}$ gas and then dissolved in $\mathrm{MeOH}$ before separation and detection by LC/APCI-MS. Quantification of samples was made against standard curves of MDA (made by hydrolysis of 1,1,3,3tetraethoxypropane (TEP) in $1 \% \mathrm{H}_{2} \mathrm{SO}_{4}\left(2 \mathrm{~h}\right.$ at $\left.20{ }^{\circ} \mathrm{C}\right)$ ), $\mathrm{HHE}$ and HNE. Standards were treated in the same way as the samples. Results are expressed as $\mu \mathrm{mol} \mathrm{L}{ }^{-1}$ sample and each sample was analyzed in 1-2 replicates. In digesta analyzed with six replicates the determined relative standard deviations (\%) were: 2.6\% (MDA), 7.6\% (HHE) and 5.6\% (HNE).

\subsection{Analysis of lipid hydroperoxides}

Hydroperoxides were determined in gastric and intestinal lumen samples according to the FOX2 assay $^{25}$ using the PeroxiDetect $^{\mathrm{TM}}$ Kit (Sigma-Aldrich, St Louis, MO, USA). Each sample was diluted 5 times in methanol:water $(90: 10)$, vortexed, incubated for $5 \mathrm{~min}$, and centrifuged at $1700 \mathrm{~g}$ for $3 \mathrm{~min}$ before the kit instructions were followed. The hydroperoxide concentrations of the samples were calculated from the absorbance readings at $560 \mathrm{~nm}$ and a standard curve made of tert-butyl hydroperoxide. The absorbance of the digestion blank at start was subtracted from all samples. Samples were analyzed in triplicates and expressed as $\mu \mathrm{mol} \mathrm{L}{ }^{-1}$.

\subsection{Statistical analysis}

Two to four replicates of each test meal were digested in the tiny-TIM system and for screening purposes, single digestions of some test meals were also included (Table 2). Analytical replicates are given in each method section. Statistical differ- ences in lipid composition of intake samples, between digests from the different test meals, as well as between different time points from a given digestion were determined by ANOVA using Tukey HSD as post hoc test (IBM SPSS Statistics 19, IBM Corp., NY, USA). Lipid composition data were analyzed by Kolmogorov-Smirnov test to verify normality. The level of significance was set at $p<0.05(95 \%)$.

\section{Results and discussion}

\subsection{Properties of the dynamic gastrointestinal in vitro model}

The TIM system, the dynamic, multi-compartmental GI model, was used and validated previously for fat digestion experiments. ${ }^{26-28}$ Here, the tiny-TIM was used to investigate GI oxidation from fish and fish oil. After ingestion, the meal was subjected to continuous secretion of gastric and intestinal fluids, gastric emptying, and continuous removal of small compounds from the intestinal compartment. The concentration of lipid peroxidation products will thus change over time independently of whether there is any production/degradation or not. In order to evaluate the fate of lipid peroxidation in the gastric and intestinal compartments, the data must be compared with the concentration changes caused by the dynamic system itself as illustrated with Patent blue in Fig. 1. At 90 min approximately $45 \%$ of the initial concentration was present in the gastric lumen and a peak was reached in the intestinal lumen (35\%).

\subsection{Initial lipid composition of the test meals}

Two common food fish species rich in n-3 LC-PUFA were chosen for this study, herring and salmon. Each meal consisted of $150 \mathrm{~g}$ in total, whereof $50 \mathrm{~g}$ fish mince, $8.75 \mathrm{~g}$ herring oil, or $44 \mathrm{~g}$ herring oil emulsion (Table 1). The total lipid intake via the test meals was standardized at approximately $8.75 \mathrm{~g}$ for comparison of GI oxidation between fish mince and

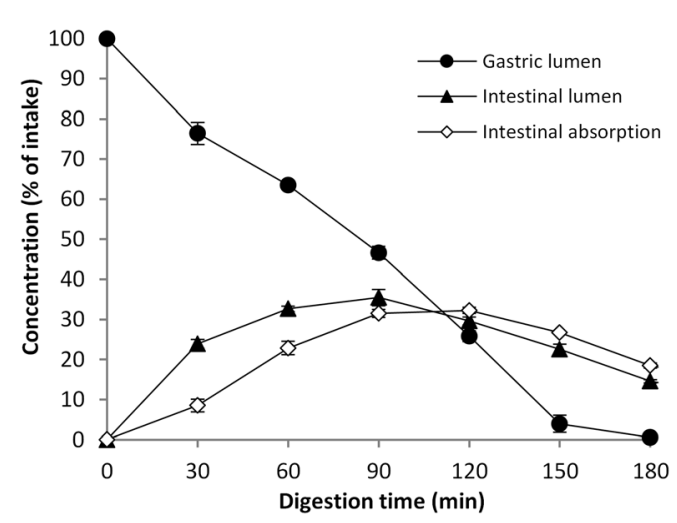

Fig. 1 Concentration of Patent Blue $V$ marker, expressed as \% of dose, in the gastric and intestinal compartments and in intestinal filtrate during dynamic in vitro digestion in tiny-TIM. The intestinal absorption curve represents compounds passing a filter with a pore size of $50 \mathrm{~nm}$. Error bars represents (max-min)/2 of two digestions. 
Table 3 Lipid composition of oil and fish minces digested in the dynamic Gl model. Different superscript letters within one row indicate statistical differences $(p<0.05)$

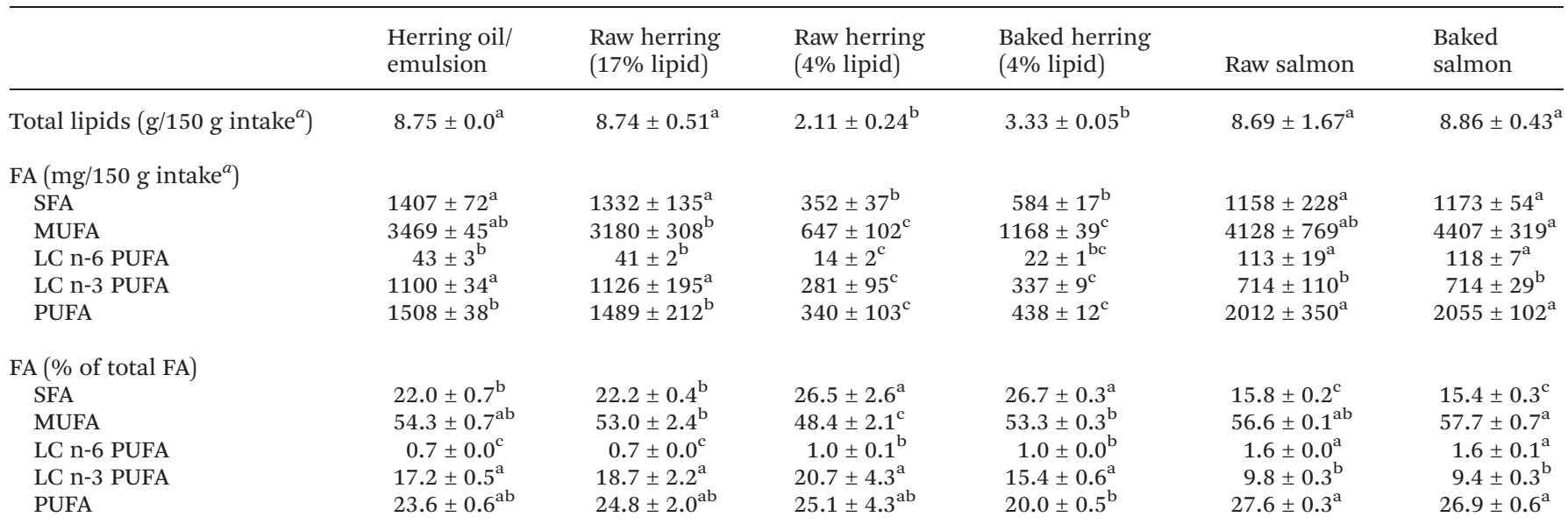

FA, fatty acid; SFA, saturated fatty acid; MUFA, monounsaturated fatty acid; LC PUFA, long chain polyunsaturated fatty acid. ${ }^{a}$ Description of the intake composition is given in Table 1.

its fractionated oil. The exact amount of total lipids and lipid composition in each test meal is given in Table 3. Extensive seasonal variation in lipid content of herring was observed for the two selected batches, $4.2 \% v s .17 .5 \%$, which represents the low and high range of normal lipid content in herring. ${ }^{29}$ The farmed salmon contained equal amounts of lipids as the highfat herring (17.4\%). Salmon had a significantly lower proportion of LC n-3 PUFA and saturated fatty acids compared to herring lipids, expressed as per cent of total fatty acids, but on the contrary a higher proportion of LC n-6 PUFA. Regarding absolute differences, salmon test meals contained significantly more LC n-6 PUFA and total PUFA than all test meals with herring lipids. As regard to LC n-3 PUFA, salmon had significantly lower amounts than herring oil and herring (17\% lipid), while it had significantly higher amounts than the raw and baked herring with low lipid content.

\subsection{Formation of MDA and HHE during digestion of herring lipids}

To evaluate the impact of the fish muscle matrix on GI oxidation, herring oil was fractionated from the herring mince (17\% lipid) and digested either as emulsified or crude oil, both with equal amount of total lipids per digestion ( $8.75 \mathrm{~g}$ ) as $50 \mathrm{~g}$ raw herring mince. Herring mince containing a lower lipid content was also included (4\% lipid, $2 \mathrm{~g}$ per digestion). General for all test meals during the gastric digestion was the bell-shaped curves for MDA and HHE (Fig. 2A and B) indicating the formation of aldehydes despite the dilution behavior of the dynamic system (Fig. 1). Raw herring, both lipid levels, developed higher concentrations of MDA and HHE compared to meals with herring oil. Based on maximum MDA and HHE levels, the different herring meals were ranked: herring $(17 \%$ lipid) $>$ herring ( $4 \%$ lipid) $\gg$ herring oil emulsion $>$ herring oil. Both MDA and HHE levels peaked at 90 min of digestion of herring ( $17 \%$ lipid), reaching a concentration of $24 \mu \mathrm{M}$ and
$840 \mathrm{nM}$, respectively. This was significantly higher than that of the other herring products. For herring ( $4 \%$ lipid), the MDA and HHE levels increased more rapidly during the first $30 \mathrm{~min}$, building a plateau between $30-90 \mathrm{~min}$, then followed by a drop in accordance with the continued "dynamic dilution". The same appearance was seen for fractionated oils, where the highest obtained concentration for emulsified herring oil was 1.6 $\mu \mathrm{M}$ MDA and $72 \mathrm{nM}$ HHE with corresponding numbers for non-emulsified oil being $0.3 \mu \mathrm{M}$ and $28 \mathrm{nM}$, respectively.

Herring (17\% lipid) differentiated even more from the other test meals regarding the intestinal production of MDA (Fig. 2C). An almost linear increase of MDA in the intestinal lumen occurred until $150 \mathrm{~min}$ of digestion reaching $23 \mu \mathrm{M}$. The level declined gradually to $4 \mu \mathrm{M}$ until the end of the digestion (180 to $300 \mathrm{~min}$, not all data shown). While herring (17\% lipid) reached a similar concentration of MDA in the gastric lumen as in the intestinal lumen $(24 \mu \mathrm{M}$ at $90 \mathrm{~min}$ and $23 \mu \mathrm{M}$ at $150 \mathrm{~min}$, respectively), herring (4\% lipid) reached $15 \mu \mathrm{M}$ in the gastric compartment versus $4 \mu \mathrm{M}$ in the intestinal compartment (Fig. 2A and C). This could partly be explained by the rapid production of MDA in herring ( $4 \%$ lipid) in the gastric lumen, which, when emptied into the intestinal lumen, caused a small peak at $90 \mathrm{~min}$ and a steady state from 90 to $180 \mathrm{~min}$, indicating a low intestinal production of MDA. For emulsified and crude herring oil, the slight increase of MDA over time, in combination with the higher values found in the intestinal lumen compared to the gastric lumen, indicated that the peroxidation proceeded in the intestinal phase, however at low levels. Increased MDA values during static in vitro digestion of fish oil containing test meals have also been reported by others. Kristinova et al. ${ }^{14}$ determined a twofold increase in MDA equivalents (measured as TBARS) after gastric digestion of herring lipids. Further, KenmogneDomguia et al. ${ }^{15}$ obtained elevated MDA levels during gastric 

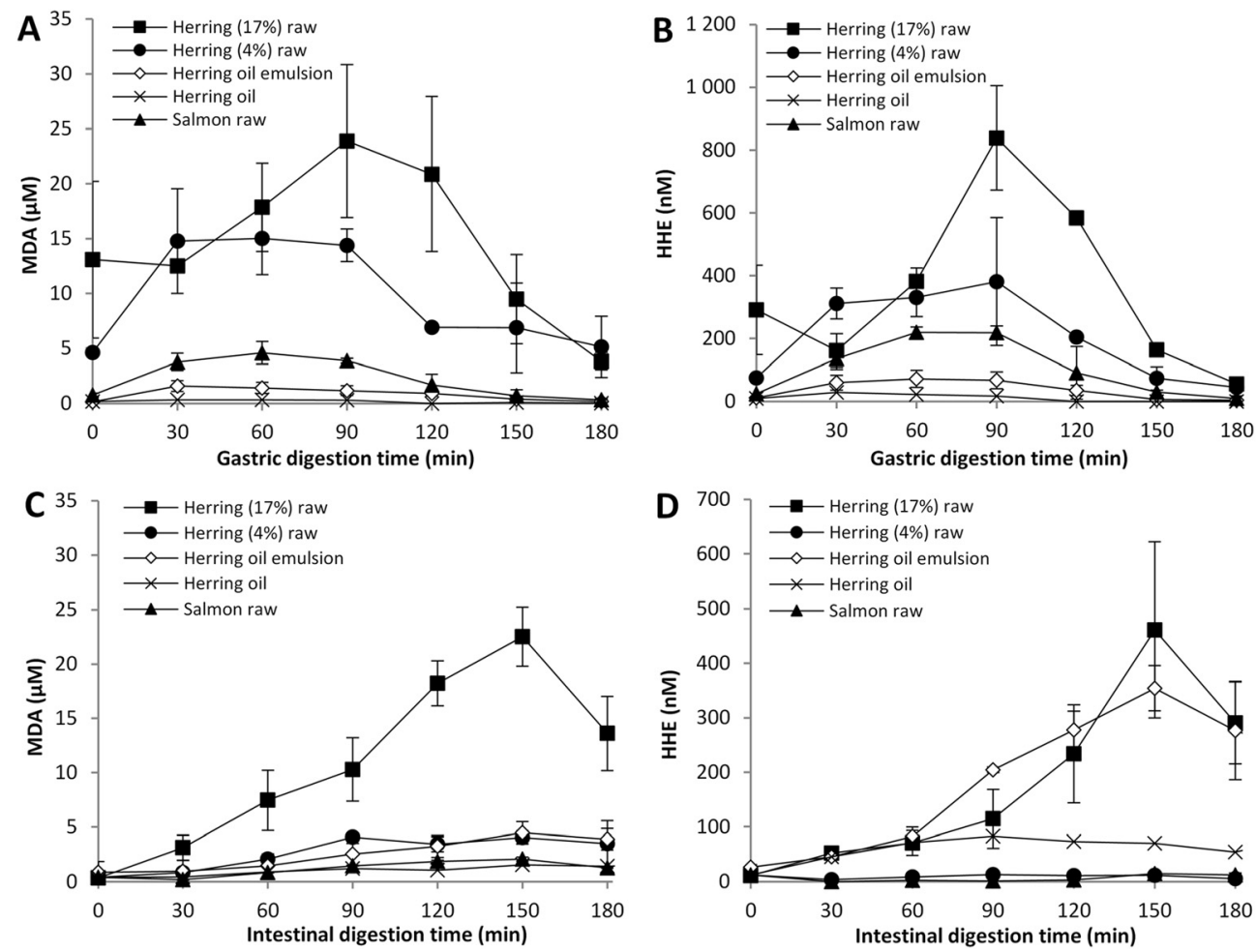

Fig. 2 Concentration of MDA and HHE in gastric ( $A$ and $B$ ) and intestinal lumen ( $C$ and $D$ ) during dynamic in vitro digestion of test meals containing fish lipids. Values at time zero in the gastric lumen $(A$ and $B)$ represent the concentration in the intake sample. Digestion blanks, containing $<0.36 \mu M$ MDA and $<6 \mathrm{nM} \mathrm{HHE}$ at all sampling points, have been subtracted from each test meal. Lipid content of the fish mince is indicated in the legend. Herring oil and baked herring + ascorbic acid were digested once and have no error bars.

digestion of emulsions containing a mix of tuna oil and oleic sunflower oil with the addition of $20 \mu \mathrm{M}$ metmyoglobin. The MDA concentrations continued to increase during subsequent intestinal digestion. Raised TBARS levels during both the gastric and intestinal step were also confirmed in our earlier static digestion studies on GI oxidation of cod liver oil. ${ }^{13,30}$ When raw herring mince (17\% lipid) and herring oil were subjected to static GI digestion using the procedure described in Larsson et al. ${ }^{13}$ the increment of TBARS after the gastric and the intestinal step compared to the start values were 7 - and 13-fold in herring mince versus 21- and 32-fold in herring oil (unpublished data). However, the initial TBARS value of herring mince was much higher compared to that of herring oil. The generated TBARS concentration after gastric digestion of herring mince $(\sim 1730 \mu \mathrm{mol}$ per $\mathrm{kg}$ lipid; $89 \mu \mathrm{mol}$ per $\mathrm{L}$ digesta) was $\sim 75$ times higher than the corresponding value after digesting herring oil (22 $\mu \mathrm{mol}$ per $\mathrm{kg}$ lipid; $1.2 \mu \mathrm{mol}$ per $\mathrm{L}$ digesta). The large relative difference in MDA concentration between herring mince and its isolated herring oil during static digestion was thus confirmed by the dynamic digestion presented here.

HHE data did not completely follow the same pattern as MDA during the intestinal digestion (Fig. 2D and C, respectively). Before $60 \mathrm{~min}$ of digestion, the test meals with $8.75 \mathrm{~g}$ lipids showed inseparable HHE concentrations, despite their different concentrations developed in the gastric lumen
(Fig. 2B and D). However, between 90 and 180 min of digestion, the HHE levels in the intestinal lumen from herring (17\% lipid) and emulsified herring oil increased remarkably, with a peak at $150 \mathrm{~min}$, while the crude herring oil leveled off after $90 \mathrm{~min}$. The higher HHE concentration with herring oils in intestinal lumen compared to that in gastric lumen, especially with the emulsified oil, proofs a continued intestinal oxidation. Interestingly, the HHE levels with herring (4\% lipid) in the intestinal lumen were much lower than expected when taking into account the released amount from the gastric lumen (Fig. 2B and D), a scenario in conformity with the corresponding MDA values. It is possible that proteolysis, caused by the digestion, generated more exposed amino groups that could form covalent adducts with HHE and MDA, which will affect the detectable lipid oxidation products. The fact that herring (17\% lipid) gave rise to significantly higher HHE and MDA levels than herring (4\% lipid) in the intestinal lumen could be a molar effect. HHE derives uniquely from n-3 PUFA, while MDA can be produced from PUFA containing minimum 3 double bonds. ${ }^{31}$ Herring (17\% lipid) contained e.g. four times more LC n-3 PUFA than herring (4\% lipid), which hence could generate higher quantities of HHE during GI digestion. Endogenous oxidants could also play a role in the observed discrepancy. Depending on the amount of lipids available for peroxidation the overall effect of pro- and antioxidants will differ. 
Emulsification of herring oil generated significantly higher concentrations of MDA and HHE during both the gastric (30-120 $\mathrm{min})$ and intestinal (60-150 $\mathrm{min})$ digestion phase compared to crude oil. It might be that the increased surface area for emulsified lipid droplets facilitated gastric oxidation and once the lipid peroxidation was initiated, propagation could continue during the remaining digestion time. No effect of emulsification on GI oxidation was seen during static in vitro digestion of cod liver oil as long as preformed oxidation products were at the same concentration. ${ }^{13}$

\subsection{Comparison of herring and salmon}

To evaluate the role of endogenous pro- and antioxidants for the susceptibility to GI oxidation, herring with $17 \%$ lipids was compared to salmon (17\% lipids). Results showed significantly higher values of MDA and HHE during digestion of raw herring compared to salmon with similar amounts of lipids (Fig. 2). In the gastric phase (Fig. 2A), a more than 5-fold higher MDA concentration was produced by herring compared to salmon $(23.9 \mu \mathrm{M}$ vs. $4.6 \mu \mathrm{M})$ and in the intestinal phase (Fig. 2C) a 10-fold difference between these samples was obtained $(22.5 \mu \mathrm{M}$ vs. $2.1 \mu \mathrm{M})$. Regarding the formation of HHE in herring compared to that in salmon, almost the same increase was found in the gastric phase (3.8-fold), while a 33-times higher HHE intestinal level was developed in herring compared to salmon (Fig. 2B and D).

The observed species differences could be related to their different characteristics. Herring has a relatively large proportion of dark muscle, which contains high heme-protein levels known to act pro-oxidative, e.g. by promoting decomposition of lipid hydroperoxides. Autooxidation of heme-proteins leading to its even more reactive met-form can be accelerated under gastric conditions with a low $\mathrm{pH}$ and mild proteolysis. ${ }^{17}$ Addition of $11.5 \mu \mathrm{M} \mathrm{Hb}$, which was the concentration determined in herring mince, was reported to rapidly enhance lipid peroxidation in cod liver oil emulsion subjected to static in vitro GI digestion. ${ }^{13}$ Salmon, on the other hand, has lower heme-protein levels and also contains astaxanthine and canthaxanthine with conjugated double bonds able to scavenge radicals. So, we hypothesize that salmon has a superior antioxidant to pro-oxidant balance.

Another difference between the fish species affecting lipid peroxidation is the relative proportion of unsaturated fatty acids. As reported in Table 3, herring contains significantly larger quantities of LC n-3 PUFA than salmon, which partly could explain the reported higher HHE values. In parallel, salmon developed higher amounts of HNE in the gastric phase compared to herring, which is in agreement with its higher n-6 PUFA content (data not shown).

Finally, it should be noted that the amount of MDA and HHE before digestion also differed significantly between the species, which could influence the degree of GI oxidation. ${ }^{30}$ Herring (17\% lipid) contained $39 \mu \mathrm{mol}$ MDA per $\mathrm{kg}$ mince and $870 \mathrm{nmol}$ HHE per $\mathrm{kg}$ mince at start, while raw salmon contained 2.2 $\mu \mathrm{mol}$ MDA per $\mathrm{kg}$ mince and $72 \mathrm{nmol}$ HHE per $\mathrm{kg}$ mince. Corresponding starting values of raw herring ( $4 \%$ lipid) were in between herring (17\% lipid) and salmon $(14 \mu \mathrm{mol}$ MDA per $\mathrm{kg}$ mince and $220 \mathrm{nmol}$ HHE per $\mathrm{kg}$ mince) and it also yielded in between-levels of MDA and HHE during GI digestion. However, salmon had the highest increase in relative aldehyde concentration during 30-120/150 min of gastric digestion (ESI figure $\dagger$ ), but a high relative value is also more easily obtained with a low initial concentration. Despite the decline in absolute aldehyde concentrations between 120-180 min of digestion for all fish samples (Fig. 2A and B), the relative aldehyde formation continued to increase. It should be noted though that the very high relative aldehyde values at the end of the digestion (180 min) becomes unreliable because of the very low comparable concentration. For all three test meals, the relative change was almost identical for MDA and HHE.

\subsection{Effect of oven baking}

Oven baking itself caused a significant increase of MDA in salmon (7.6 $\mu \mathrm{M} v$ s. $0.74 \mu \mathrm{M}$ in the intake sample) as shown in Fig. 3A. Also HHE levels were raised by cooking, $58 \mu \mathrm{M}$ in intake samples of oven baked salmon versus $24 \mu \mathrm{M}$ in raw salmon (Fig. 3B). In contrast, the MDA and HHE levels of herring ( $4 \%$ lipid) were reduced by $\sim 45 \%$ after cooking (measured in intake samples), despite the relative increase of lipids ( $\mathrm{g}$ lipid per $\mathrm{g}$ wet weight) due to e.g. moisture loss (Table 3).

During subsequent gastric digestion the MDA and HHE levels were slightly elevated in cooked salmon compared to raw salmon. Also oven baked herring mince evolved higher MDA and HHE levels than raw herring mince during 60-120 min of digestion and peaked at $26 \mu \mathrm{M}$ MDA and $~ 700 \mathrm{nM}$ HHE at $90 \mathrm{~min}$. However, the variance for the herring replicates was extensive.

Higher MDA and HHE levels were observed for oven baked salmon in the intestinal lumen compared to raw salmon (Fig. 3C and D), with a significant difference in MDA between raw and cooked salmon already after $30 \mathrm{~min}$, reflecting the difference in intake concentration. Maximum MDA levels obtained in intestinal lumen were $3.4 \mu \mathrm{M}$ for cooked salmon versus $2.1 \mu \mathrm{M}$ for raw salmon. Cooking of herring (4\% lipid) had no impact on the amount of MDA and HHE found in the intestinal lumen. In general, low concentrations of MDA and HHE were determined in the intestinal lumen during digestion of herring (4\% lipid) and salmon.

Earlier studies on changes in lipid quality during cooking of fish have resulted in inconsistent results. For example, in trout, anchovy, saithe and carp secondary oxidation products were reported to increase during cooking, ${ }^{32-35}$ while diminished levels of both peroxide values and anisidine values were determined in herring and trout after heat treatment. ${ }^{36,37}$ Van Hecke et al. ${ }^{5}$ have also shown that MDA and HNE levels in pork were elevated by cooking, and during subsequent static in vitro digestion the levels of lipid peroxidation products remained higher in the cooked sample compared to the raw sample. 

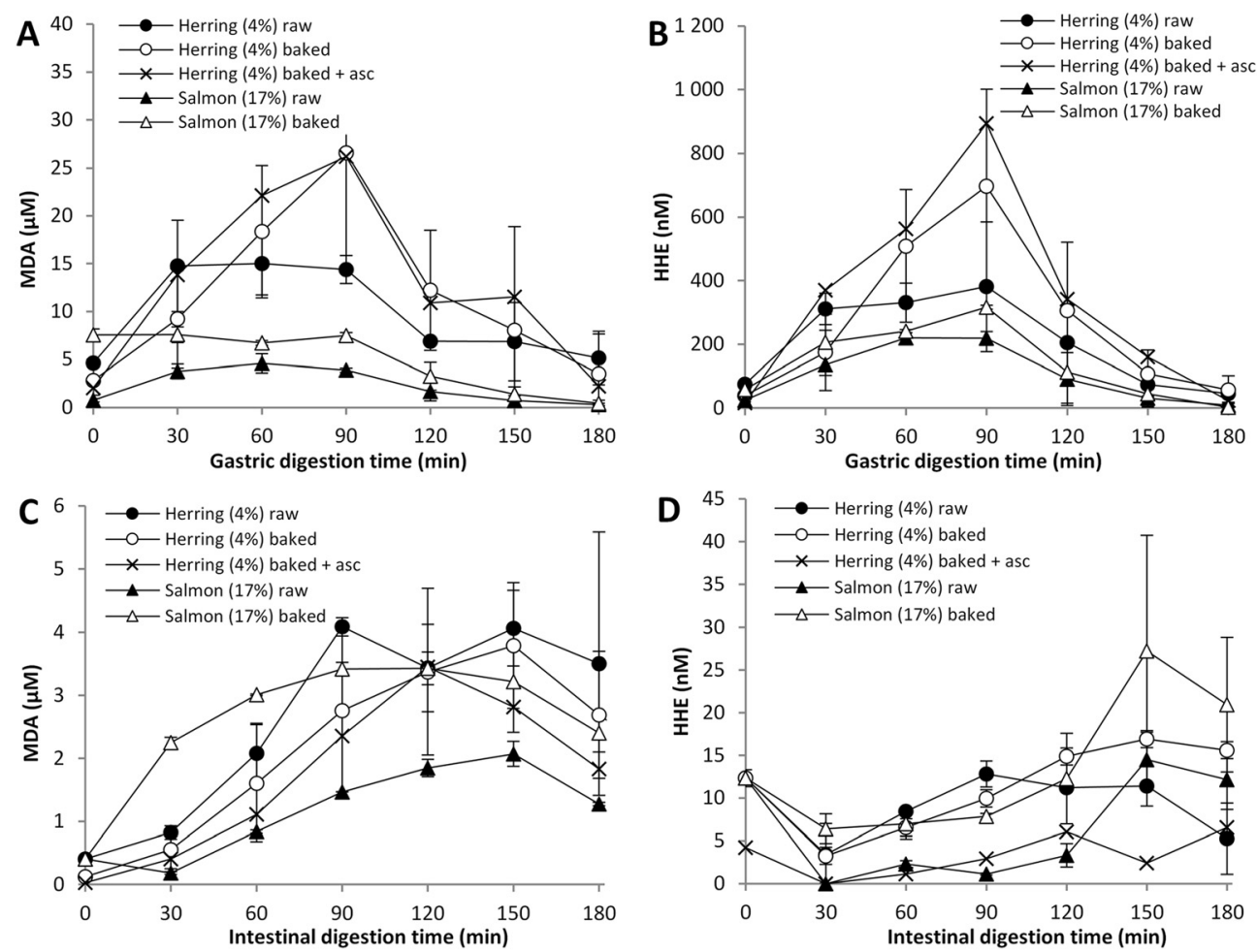

Fig. 3 Concentration of MDA and HHE in gastric (A and B) and intestinal lumen (C and D) during in vitro digestion of raw and oven baked fish mince. Values at time zero in the gastric lumen ( $A$ and $B$ ) represent the concentration in the intake sample. Lipid content of the fish mince is indicated in the legend.

\subsection{Influence of ascorbic acid in gastric secretions on the formation of MDA and HHE}

Ascorbic acid is a well-known oxidant which can play several functions on lipid peroxidation. It has antioxidant properties, especially in synergy with tocopherol, but also a pro-oxidative effect $e$.g. by reducing $\mathrm{Fe}^{3+}$ to $\mathrm{Fe}^{2+}$, which accelerates the lipid radical formation either via direct reaction with lipid hydroperoxides or by the formation of hydroxyl radicals via Fenton chemistry. ${ }^{38}$ Endogenous ascorbic acid is found at low concentration in gastric juice, ${ }^{39}$ however, it was not included in the standardized digestion protocol. Therefore, one digestion experiment with oven baked herring was made to test the oxidative effect of $85 \mu \mathrm{M}$ ascorbic acid in simulated gastric secretions, which then comes on top of the ascorbic acid provided by the herring itself. The results indicated very similar MDA and HHE values during digestion of baked herring ( $4 \%$ lipid) with and without ascorbic acid (Fig. 3). Kristinova et al. ${ }^{14}$ have previously reported a strong pro-oxidative effect of $100 \mu \mathrm{M}$ ascorbic acid when added to herring lipid emulsion and liposomes subjected to a gastric in vitro digestion.

\subsection{Formation of HNE}

The formation of HNE from fish lipids during GI digestion was difficult to interpret as interfering high values, up to $35 \mathrm{nM}$, were analyzed in blank digestions containing bread (yielding $0.2 \mathrm{~g}$ vegetable oil per intake). The HNE curves of test meals without bread peaked at 90-120 min of gastric digestion, and maximum levels reached in gastric lumen were: $9 \mathrm{nM}$ for herring oil emulsion, $17 \mathrm{nM}$ for herring (17\% lipid) and $32 \mathrm{nM}$ for oven baked herring (data not shown). Also test meals containing fish or fish oil with bread resulted in low HNE levels, with the highest response determined in oven baked herring with ascorbic acid $(55 \mathrm{nM}$, without blank subtraction). During the intestinal digestion, the emulsified herring oil (without bread) was the only test meal with pronounced higher HNE values compared to its corresponding digestion blank, and it peaked at $30 \mathrm{nM}$ at $60 \mathrm{~min}$. Low production of HNE was expected from fish alone, as it contains relatively low levels of n-6 PUFA and even less of LC n-6 PUFA. However, it is difficult to explain why blanks with bread alone gave higher HNE levels than fish or fish oil meals with bread. It could indicate that HNE either reacts with compounds in the fish matrix or that fish and fish oil contributes with a strong antioxidative effect, or a combination of these two.

\subsection{Formation of lipid hydroperoxides}

In our earlier studies on cod liver oil, the lipid hydroperoxide concentrations have remained unchanged during the different steps of a static GI in vitro digestion. ${ }^{13}$ To investigate the fate of lipid hydroperoxides in a dynamic in vitro system, two test meals were selected; raw herring mince (17\% lipid) and emul- 

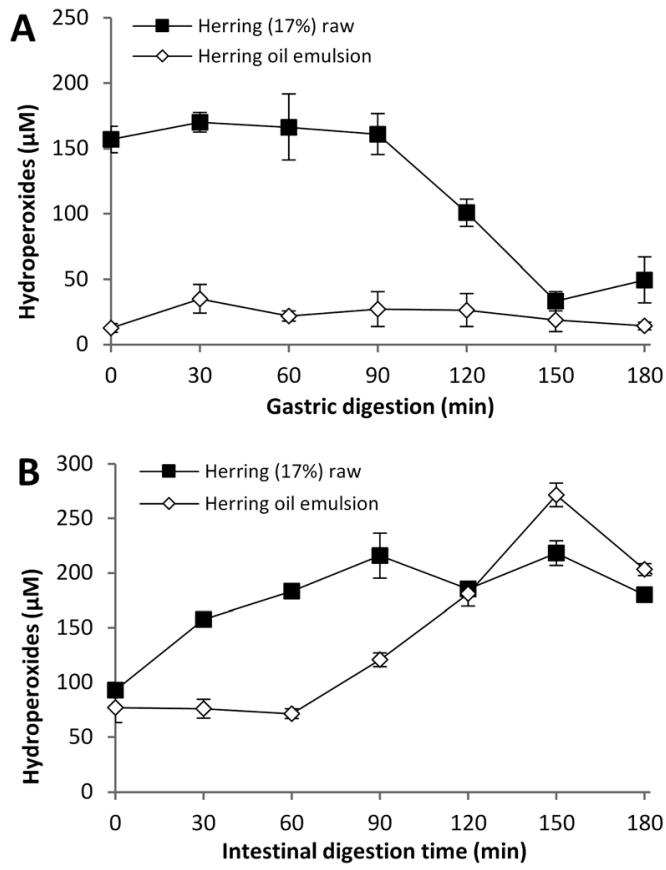

Fig. 4 Concentration of hydroperoxides in gastric (A) and intestinal lumen (B) during dynamic in vitro digestion of herring mince (17\% lipid) and emulsified herring oil. Values at time zero in the gastric lumen (A) represent the concentration in the intake sample. Results are expressed as mean \pm SD. Lipid content of the fish mince is indicated in the legend.

sified herring oil. A 2- and 4-fold increase of lipid hydroperoxides was observed during the first $90 \mathrm{~min}$ of gastric digestion (Fig. 4) for herring mince and emulsified herring oil, respectively, when taking into consideration the theoretical linear dilution illustrated in Fig. 1. However, the actual concentration of hydroperoxides in the gastric lumen between 0-90 min remained relatively stable; $\sim 160 \mu \mathrm{M}$ for herring mince and $\sim 25 \mu \mathrm{M}$ for herring oil emulsion. Values at time zero for herring mince and herring oil emulsion were $2.7 \mu \mathrm{mol}$ per $\mathrm{g}$ lipid and $0.2 \mu \mathrm{mol}$ per $\mathrm{g}$ lipid, respectively.

A significant increase in lipid hydroperoxides occurred in the intestinal lumen for both test meals, but the raise evolved earlier for herring mince compared to the emulsion. This was in accordance with the initially higher amounts of hydroperoxides in the intake sample of the herring mince compared to herring oil emulsion. Remarkably, the emulsified herring oil reached the highest maximum level, with a peak of $\sim 270 \mu \mathrm{M}$ at $150 \mathrm{~min}$.

The formation of primary peroxidation products in the gastric lumen was in agreement with the study by Maestre et $a l .{ }^{16}$ They reported an almost 2 -fold increase of conjugated dienes/g lipid of minced raw mullet after 90 min of a dynamic in vitro digestion. Similar results were obtained for fish oil containing emulsions undergoing static gastric in vitro digestions. ${ }^{14,15}$ Kenmogne-Domguia et al. ${ }^{15}$ reported a continued peroxidation in the intestinal phase during static digestion, and Maestre et al. ${ }^{16}$ determined a weak increase of conjugated dienes in intestinal filtrate during dynamic digestion.

\subsection{MDA and HHE concentration in intestinal lumen and after intestinal absorption}

Intestinal compounds with a diameter $<50 \mathrm{~nm}$ passed the semipermeable membrane and were regarded accessible for intestinal absorption. As a comparison, mixed micelles, which mainly consists of bile salts, phospholipids, free fatty acids and monoglycerides, ${ }^{40}$ have a diameter of $\sim 8 \mathrm{~nm}^{41}$ and diffuse through the unstirred water layer of the intestinal mucosa and are then absorbed by enterocytes. During in vitro digestion, the concentrations of peroxidation products in the intestinal lumen were determined at $30 \mathrm{~min}$ intervals as snap-shot samples, while the intestinal absorption was collected in 30 min aliquots, thus representing the average concentration during these $30 \mathrm{~min}$ sampling periods. So, the two samplings are not directly comparable, but a rough picture of their correlation is obtained and can be related to the dilution curves given in Fig. 1. Herring (17\% lipid) was selected as a representative sample to illustrate the concentration differences of the two sample types during intestinal digestion (Fig. 5). Higher concentrations of MDA and HHE were determined in intestinal lumen than in intestinal absorption samples during the first 180-240 min of digestion, which partly can be due to that formed aldehydes in the gastric part are emptied into the intestinal lumen, leading to an immediate increase in the intestinal lumen, but a delayed increase in the absorption sample. Further, incomplete digestion of the fish matrix results in a build-up of substrate in the lumen. After 180 or 240 to $300 \mathrm{~min}$ of digestion the opposite situation is seen,
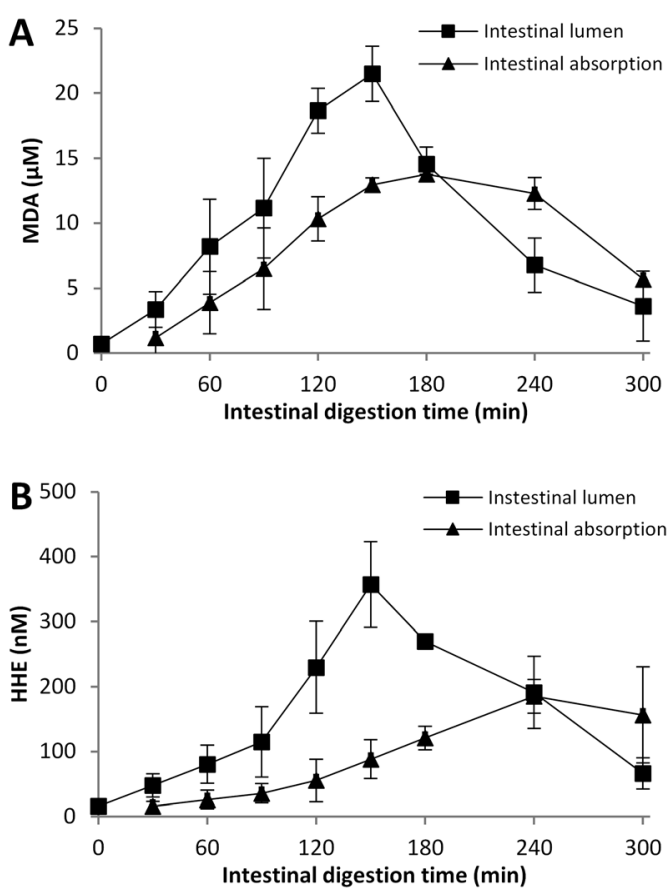

Fig. 5 Concentration of MDA (A) and HHE (B) in intestinal lumen (spot samples) and in intestinal absorption samples (collected in 30 min time periods) during dynamic in vitro digestion of raw herring mince $(17 \%$ lipid). 
with a higher concentration of aldehydes in intestinal absorption samples compared to lumen samples. The concentrations of MDA and HHE in samples from intestinal lumen and absorption were, however, of the same magnitude, concluding that any toxicity of these aldehydes can lead to not only local, but also systemic effects after uptake.

\subsection{Evaluation of formed oxidation products in relation to potential health risks}

The electrophilic property of $\alpha, \beta$-aldehydes like MDA, HHE and HNE makes them highly reactive. It has been described in animal studies that high doses of oxidized lipids can be incorporated by the liver into VLDL and thus accelerate atherosclerosis and cause organ toxicity. ${ }^{31,42,43}$ Awada et $a .^{44}$ demonstrated that a high-fat diet containing moderately oxidized n-3 PUFA increased plasma levels of HHE and enhanced plasma inflammatory markers in mice. Further, orally administrated HHE in mice or exposure of HHE to Caco-2 cells led to the formation of $\mathrm{HHE}$ histidine Michael adducts. Also in humans, oxidized dietary fatty acids were absorbed and incorporated into chylomicrons or chylomicron remnants, leading to circulating oxidized lipoproteins. ${ }^{45}$ Similar negative results were not evidenced by a human study where healthy subjects consumed $8 \mathrm{~g}$ of oxidized fish oil (PV = $18 \mathrm{mEq}$ per $\mathrm{kg}$ oil; anisidine value $=9$ ) per day for seven weeks. ${ }^{46,47}$ Neither circulating levels of oxidized LDL, lipid peroxidation products (HHE, HNE), nor markers for oxidative stress and inflammation were significantly affected compared to the control group consuming non-oxidized fish oil. Similar median values of HHE and HNE in plasma of both groups were reported; $3.1 \mathrm{ng}$ HHE $\mathrm{mL}^{-1}$ and $4.3 \mathrm{ng} \mathrm{HNE}$ per $\mathrm{mL}$, which corresponds to $27 \mathrm{nM}$ for both aldehydes. Our determined HHE concentrations in intestinal lumen after digesting non-oxidized herring oil peaked at $83 \mathrm{nM}$ (Fig. 2D), thus exceeding the plasma levels reported by Ottestad et al. ${ }^{46}$ A difference can be expected since our assessments only indicate the amount present in the intestinal lumen without further metabolic processing, including the cellular uptake of aldehydes and subsequent transport to the plasma. Based on the recent quality investigation of encapsulated fish oil supplements on the New Zeeland market, ${ }^{48}$ the oxidized fish oil in the human study of Ottestad et al. ${ }^{46}$ was not extremely oxidized compared to what consumers taking fish oil supplements may ingest. In fact, several supplements matched or exceeded the oxidized fish oil used in the study of Ottestad et al. with respect to peroxide value (PV), anisidine value or Totox. This is despite the selection criterion of 12-24 months remaining of the best-before date. ${ }^{44}$ The herring oil used in our study had a PV of $1.4 \mathrm{mEq}$ per $\mathrm{kg}$ lipid, compared to 4 and $18 \mathrm{mEq}$ per $\mathrm{kg}$ lipid in the non-oxidized and oxidized oil used in the study of Ottestad et al. ${ }^{46}$ Secondary oxidation products were unfortunately not comparably expressed. In conformity with herring oil, raw herring mince (17\% lipid) had a low PV, $2.1 \mathrm{mEq}$ per $\mathrm{kg}$ lipid before digestion. But the secondary oxidation product HHE was almost 30-fold higher in the mince than the herring oil, generating a peak concentration of $460 \mathrm{nM}$ in the intestinal lumen. Also herring oil emulsion, with similar HHE concentration as herring oil at start, reached a high HHE level (350 nM) in the intestinal lumen during digestion. Apparently, both initial lipid quality and the form in which the lipids are supplied will affect the amount of lipid peroxidation products produced. It is thus most likely that people will consume products with higher levels of oxidation products than those used in the study by Ottestad et $a l^{46}$ Furthermore, we show that neither the MDA nor the HHE levels returned to its base line levels during digestion for $300 \mathrm{~min}$ (end points data not shown). This illustrates that the intestine may be exposed to elevated aldehyde concentrations during a long period.

In this study, the highest determined levels of MDA $(\sim 25 \mu \mathrm{M})$, HHE $(\sim 850 \mathrm{nM})$ and HNE $(\sim 55 \mathrm{nM})$ were achieved with raw herring (17\% lipid) and/or baked herring ( $4 \%$ lipid) in gastric lumen. However, high levels in the gastric lumen were not directly correlated with high levels in the intestinal lumen and vice versa, which means that the exposure of toxic aldehydes can vary extensively in different parts of the digestion system. To judge whether the measured concentrations are cytotoxic, these values can be related to the $\mathrm{LC}_{50}$ values determined in various cell types ranging from $600 \mu \mathrm{M}$ for MDA and $20-60 \mu \mathrm{M}$ for both HHE and HNE. ${ }^{18,49}$ The GI concentrations found in our study are far below the reported $\mathrm{LC}_{50}$ values. It should, however, be remembered that we analyzed free aldehydes. The aldehydes which already had exerted their toxicological nucleophilic attack forming Michael adducts, Schiff base cross-links or DNA adducts, would thus be nondetectable. ${ }^{50}$ The same would be true for aldehydes detoxified by e.g. glutathione. Awada et al. ${ }^{44}$ have shown increased HHEprotein adducts in the duodenum and the jejunum in mice after oral administration of $10 \mathrm{mg}$ per $\mathrm{kg}$ b.w. of HHE. As e.g. genotoxic concentrations can be lower than reported cytotoxic concentrations, the risk connected to elevated levels of these aldehydes in the long run on human health is more difficult to evaluate.

Attempts have been made by others to estimate the average daily intake of MDA, HHE and HNE. An estimation of the Korean daily exposure to HHE and HNE from fish, shellfish and vegetable oil resulted in $1.6 \mu \mathrm{g}$ day $^{-1}$ and $2.7 \mu \mathrm{g}$ day $^{-1}$, respectively, but was largely increased when fried foods were added (total $16.1 \mu \mathrm{g}$ day $^{-1}$ ). ${ }^{51}$ A deterministic exposure assessment in Belgium concluded that "fresh and frozen salmon" was the main contributor to the daily intake of HHE among the selected food categories with a mean of $1.9 \mu \mathrm{g}$ day ${ }^{-1} \cdot{ }^{52} \mathrm{On}$ the contrary, each of the following food categories: dry nuts, French fries, fried snacks, and cured minced raw meat products contributed twice as much as fresh and frozen salmon, which contributed with $17 \mu \mathrm{g}$ MDA per day for a person weighing $60 \mathrm{~kg}$. Total daily exposure of MDA was $\sim 230 \mu \mathrm{g}$. Both studies concluded that there is probably no risk to consume the estimated daily intake of these aldehydes for human health. As a comparison, $100 \mathrm{~g}$ of the fish used in our study contributed with $0.83-10 \mu \mathrm{g}$ HHE and 16-280 $\mu \mathrm{g}$ MDA, where raw salmon and raw herring (17\% lipid) represents the lower and upper values, respectively. Herring oil contributed to 
lower amounts than salmon. A daily consumption of $100 \mathrm{~g}$ of the raw herring (17\% lipid) as used in this study would thus contribute to nearly the reported estimated daily intake of HHE and MDA. However, as shown in this study, the continued formation of aldehydes during digestion means that the GI tract will be exposed to larger amounts than what is present in the food initially. It should be emphasized that we used the fish as fresh as possible. More aged fish with a higher amount of preformed lipid peroxidation products would probably yield higher concentrations and total amounts of aldehydes during subsequent GI digestion. As a precaution, lipid peroxidation should thus be prevented as much as possible prior to ingestion; both for sensory reasons and to limit further oxidation risk in the GI tract. In the future, it is important to study the impact of a whole meal, as fish lipids are seldom consumed alone. Certain antioxidants in accompanying meal constituents are known to slow down oxidation during simulated digestion, e.g. catechin, ${ }^{4}$ caffeic acid, ${ }^{14}$ tocopherols ${ }^{9}$ and melanoidins, ${ }^{8}$ while other compounds may increase GI oxidation, e.g. iron $^{14}$ and metMb. ${ }^{9,53}$

\section{Conclusion}

This study demonstrates that the concentrations of MDA and HHE in gastric lumen increase during digestion of fish and fish oil, despite constant gastric fluid secretion contributing to a dilution of pre-formed and continuously formed oxidation products of the test meal. Raised aldehyde levels were also determined in the intestinal lumen during digestion. Levels of oxidation products in intestinal lumen, and not least following intestinal absorption, indicate that the intestines will be exposed to a long-lasting elevation of aldehydes after ingestion. Whether these levels will lead to deleterious local or systemic effects are unknown and need to be investigated in more detail. In addition, we showed that GI oxidation of fish or fish oil occurs without any addition of external pro-oxidants, such as iron or heme-proteins. The aldehyde concentrations found during dynamic digestion of fresh fish and fish oil were relatively low compared to those found in static digestion studies of e.g. cooked turkey meat, ${ }^{4,54}$ herring lipids (unpublished) or lipid emulsions, ${ }^{15}$ the latter with addition of metMb. It should, however, be stressed that during these static digestions no oxidation products were removed by simulated absorption. One clear advantage of using dynamic digestion methods as opposed to static ones, is the possibility to study momentary oxidation product levels in lumen and absorption samples, hereby reflecting the exposure kinetics.

\section{Acknowledgements}

The authors thank Nils-Gunnar Carlsson for technical assistance with the aldehyde analyses and Annette Almgren for the hydroperoxide analyses. This work was financially supported by FORMAS (The Swedish Research Council for Environment,
Agricultural Sciences and Spatial Planning, Project 222-20071007) and Nordic Innovation Centre (SAFEFOODERA, Project 08202).

\section{References}

1 E. B. Schmidt, H. Arnesen, J. H. Christensen, L. H. Rasmussen, S. D. Kristensen and R. De Caterina, Thromb. Res., 2005, 115, 257-262.

2 P. C. Calder, Lipids, 2004, 39, 1147-1161.

3 B. Halliwell, K. Zhao and M. Whiteman, Free Radical Res., 2000, 33, 819-830.

4 S. Gorelik, T. Lapidot, I. Shaham, R. Granit, M. Ligumsky, R. Kohen and J. Kanner, J. Agric. Food Chem., 2005, 53, 3397-3402.

5 T. Van Hecke, E. Vossen, L. Y. Hemeryck, J. Vanden Bussche, L. Vanhaecke and S. De Smet, Food Chem., 2015, 187, 29-36.

6 M. Kuffa, T. J. Priesbe, C. G. Krueger, J. D. Reed and M. P. Richards, J. Funct. Foods, 2009, 1, 208-216.

7 L. Tesoriere, D. Butera, C. Gentile and M. A. Livrea, J. Agric. Food Chem., 2007, 55, 8465-8471.

8 D. Tagliazucchi, V. Elena and C. Angela, J. Agric. Food Chem., 2010, 58, 2513-2519.

9 H. B. Kenmogne-Domguia, A. Meynier, C. Boulanger and C. Genot, Food Dig., 2012, 3, 46-52.

10 B. Lorrain, O. Dangles, M. Loonis, M. Armand and C. Dufour, J. Agric. Food Chem., 2012, 60, 9074-9081.

11 E. Goicoechea, E. F. A. Brandon, M. H. Blokland and M. D. Guillen, Food Chem. Toxicol., 2011, 49, 115-124.

12 M. Tarvainen, A. Phuphusit, J. P. Suomela, A. Kuksis and H. Kallio, J. Agric. Food Chem., 2012, 60, 3564-3579.

13 K. Larsson, L. Cavonius, M. Alminger and I. Undeland, J. Agric. Food Chem., 2012, 60, 7556-7564.

14 V. Kristinova, I. Storrø and T. Rustad, Food Chem., 2013, 141, 3859-3871.

15 H. B. Kenmogne-Domguia, S. Moisan, M. Viau, C. Genot and A. Meynier, Food Chem., 2014, 152, 146-154.

16 R. Maestre, J. D. Douglass, S. Kodukula, I. Medina and J. Storch, J. Nutr., 2013, 143, 295-301.

17 C. U. Carlsen and L. H. Skibsted, J. Agric. Food Chem., 2004, 52, 1675-1681.

18 H. Esterbauer, R. J. Schaur and H. Zollner, Free Radicals Biol. Med., 1991, 11, 81-128.

19 F. Biasi, C. Mascia and G. Poli, Genes Nutr., 2007, 2, 233243.

20 M. Minekus, P. Marteau, R. Havenaar and J. Huis in’t Veld, ATLA, Altern. Lab. Anim., 1995, 23, 197-209.

21 R. Havenaar, A. De Jong, M. E. Koenen, J. Van Bilsen, A. M. Janssen, E. Labij and H. J. M. Westerbeek, J. Agric. Food Chem., 2013, 61, 7636-7644.

22 C. M. Lee, B. Trevino and M. Chaiyawat, J. AOAC Int., 1996, 79, 487-492.

23 G. Lepage and C. C. Roy, J. Lipid Res., 1986, 27, 114-120. 
24 C. Tullberg, K. Larsson, N.-G. Carlsson, I. Comi, N. Scheers, G. E. Vegarud and I. Undeland, Food Funct., 2016, DOI: 10.1039/C5FO01332A.

25 J. Nourooz-Zadeh, J. Tajaddini-Sarmadi, I. Birlouez-Aragon and S. P. Wolff, J. Agric. Food Chem., 1995, 43, 17-21.

26 N. Domoto, M. E. Koenen, R. Havenaar, A. Mikajiri and B.-S. Chu, Food Sci. Nutr., 2013, 1, 409-415.

27 P. M. Reis, T. W. Raab, J. Y. Chuat, M. E. Leser, R. Miller, H. J. Watzke and K. Holmberg, Food Biophys., 2008, 3, 370381.

28 A. Helbig, E. Silletti, G. van Aken, A. Oosterveld, M. Minekus, R. Hamer and H. Gruppen, Food Dig., 2013, 4, 58-68.

29 K. N. Jensen, C. Jacobsen and H. H. Nielsen, J. Sci. Food Agric., 2007, 87, 710-718.

30 K. Larsson, K. Istenič, T. Wulff, R. Jónsdóttir, H. Kristinsson, J. Freysdottir, I. Undeland and P. Jamnik, J. Sci. Food Agric., 2015, 95(15), 3096-3106.

31 H. Esterbauer, Am. J. Clin. Nutr., 1993, 57, 779S-785S.

32 M. G. Karlsdottir, K. Sveinsdottir, H. G. Kristinsson, D. Villot, B. D. Craft and S. Arason, Food Chem., 2014, 164, 476-484.

33 S. Turhan, N. S. Ustun and H. Temiz, Int. J. Food Prop., 2011, 14, 1358-1365.

34 M. Naseri, M. Rezaei, S. Moieni, H. Hosseni and S. Eskandari, Int. J. Food Sci. Technol., 2010, 45, 1973-1979.

35 B. Tokur, Int. J. Food Sci. Technol., 2007, 42, 874-879.

36 Z. Domiszewski, Int. J. Food Sci. Technol., 2013, 48, 786793.

37 B. Regulska-Ilow and R. Ilow, Nahrung - Food, 2002, 46, 383-388.

38 S. Kojo, Curr. Med. Chem., 2004, 11, 1041-1064.

39 H. J. O’Connor, C. J. Schorah, N. Habibzedah, A. T. R. Axon and R. Cockel, Gut, 1989, 30, 436-442.

40 O. Hernell, J. E. Staggers and M. C. Carey, Biochemistry®, 1990, 2041-2056.

41 R. S. Parker, FASEB J., 1996, 10, 542-551.
42 J.-P. Suomela, M. Ahotupa and H. Kallio, Lipids, 2005, 40, 437-444.

43 I. Staprans, J. H. Rapp, X. M. Pan and K. R. Feingold, J. Lipid Res., 1996, 37, 420-430.

44 M. Awada, C. O. Soulage, A. Meynier, C. Debard, P. Plaisancié, B. Benoit, G. Picard, E. Loizon, M.-A. Chauvin, M. Estienne, N. Peretti, M. Guichardant, M. Lagarde, C. Genot and M.-C. Michalski, J. Lipid Res., 2012, 53, 2069-2080.

45 I. Staprans, X.-M. Pan, J. H. Rapp and K. R. Feingold, Mol. Nutr. Food Res., 2005, 49, 1075-1082.

46 I. Ottestad, G. Vogt, K. Retterstøl, M. C. Myhrstad, J. E. Haugen, A. Nilsson, G. Ravn-Haren, B. Nordvi, K. W. Brønner, L. F. Andersen, K. B. Holven and S. M. Ulven, Br. J. Nutr., 2012, 108, 315-326.

47 I. Ottestad, K. Retterstøl, M. C. W. Myhrstad, L. F. Andersen, G. Vogt, A. Nilsson, G. I. A. Borge, B. Nordvi, K. W. Brønner, S. M. Ulven and K. B. Holven, Nutr., Metab. Cardiovasc. Dis., 2013, 23, e3-e4.

48 B. B. Albert, J. G. Derraik, D. Cameron-Smith, P. L. Hofman, S. Tumanov, S. G. Villas-Boas, M. L. Garg and W. S. Cutfield, Sci. Rep., 2015, 5, 7928.

49 N. J. Pillon and C. O. Soulage, Lipid Peroxidation by-Products and the Metabolic Syndrome, in Lipid Peroxidation, ed. A. Catala, InTech, 2012, ch. 19, pp. 409-436.

50 K. Uchida, Prog. Lipid Res., 2003, 42, 318-343.

51 J. Surh and H. Kwon, Food Addit. Contam., 2005, 22, 701708.

52 A. Papastergiadis, A. Fatouh, L. Jacxsens, C. Lachat, K. Shrestha, J. Daelman, P. Kolsteren, H. Van Langenhove and B. De Meulenaer, Food Chem. Toxicol., 2014, 73, 51-58.

53 J. Kanner and T. Lapidot, Free Radicals Biol. Med., 2001, 31, 1388-1395.

54 O. Tirosh, A. Shpaizer and J. Kanner, J. Agric. Food Chem., 2015, 63, 7016-7023. 